\title{
MPB - A ÉPOCA DE OURO (1929-1945) E A PRÉ-BOSSA (1946-1957)
}

\author{
MPB - THE GOLDEN AGE (1929-1945) AND THE PRE-BOSSA AGE (1946-1957)
}

Fernando da Conceição Barradas ${ }^{1}$

${ }^{1}$ Professor e pesquisador da UNIPAR.

BARRADAS, F. da C. MPB - A época do ouro (1929-1945) e a Pré-Bossa (1946-1957). Akrópolis Umuarama, v. 25, n. 1, p. 69-79, jan./jun. 2017.

\section{DOI: 10.25110/akropolis.v25i1.6676}

Resumo: A Época de Ouro da MPB foi suplantada em importância apenas pela Era dos Festivais (1958-1973). Avalia-se a grandiosidade do período pelos sambas e marchinhas que representaram cinqüenta por cento das gravações do período. Pelos extraordinários compositores Noel Rosa,João de Barro e Lamartine Babo. Desse período dos quatro grandes intérpretes - Francisco Alves, Carlos Galhardo, Silvio Caldas e o maior de todos, Orlando Silva. Pixinguinha e Radamés Gnatalli criaram os padrões de orquestração da música brasileira. Ari Barroso produziu Aquarela do Brasil, música mais importante do século $X X$, e Carmem Miranda foi o nome de maior destaque. O período pré bossa novista foi marcado pelo samba canção depressivo e o baião, como novidades. Adotou gêneros internacionais, especialmente das grandes orquestras norte americanas para dançar, que tocavam gêneros com o fox e o blues; bolero, calipso, rumba como gêneros latinos. Finalmente o rock'n roll. Emergem grandes cantores, compositores que inovaram nos temas e na forma de cantar. Dorival Caymmi, Tom Jobim, Vinicius de Moraes foram expoentes do período. A pré bossa nova preparou o advento da MPBM - Moderna Música Popular Brasileira, representada por três grandes movimentos musicais inovadores: a bossa nova, a jovem guarda e a tropicália

PalaVRas-ChaVe: Cultura popular; Gêneros musicais; Movimentos musicais; Música Popular Brasileira.

ABSTRACT: The Golden Age of MPB was only overshadowed in importance by the Age of Festivals (1958-1973). The grandeur of that period is judged by the sambas and marchinhas that represented half of the recordings at the time, as well as by the remarkable composers Noel Rosa, João de Barro and Lamartine Babo. From the time of these four great interpreters, Francisco Alves, Carlos Galhardo, Silvio Caldas and the greatest of all, Orlando Silva. Pixinguinha and Radamés Gnatalli created the orchestration standards for Brazilian music. Ari Barroso produced Aquarela do Brasil, the most important song of the $20^{\text {th }}$ century, and Carmem Miranda was the most prominent artist of that time. The pre-Bossa Nova period was marked by depressive samba songs and also by baião as novelties. It adopted international genres, especially those from great North American orchestras for dancing, who played genres such as the foxtrot and the blues; as well as bolero, calypso, rumba as Latin genres. And then there was Rock'n'Roll. And great interpreters and composers emerged, who innovated in the topics and in the form of singing. Dorival Caymmi, Tom Jobim and Vinicius de Moraes were exponents of the period. The pre-Bossa Nova era prepared the ground for the advent of MPBM - Modern Brazilian Popular Music, represented by three great innovative musical movements: the Bossa Nova, the Jovem Guarda and the Tropicália.

KeYWORDS: Musical genres; Musical movements; Popular Brazilian Music; Popular culture. 


\section{INTRODUÇÃO}

As culturas, em qualquer área de atuação humana crescem por um processo cumulativo, pelo acréscimo de novos conhecimentos, de novos tipos de comportamento, passados às gerações posteriores através da educação.

A cultura é a somatória de vários elementos, de todos os esforços das gerações antepassadas que se sucederam no tempo e mais os da geração presente.

$\mathrm{Na}$ anterioridade cultural da MPB, em sua evolução cronológica, destaca-se no século $\mathrm{XVI}$, início da colonização, a música de capela destinada ao ritual litúrgico e erudito à base de órgão e cantochão. Os índios aculturados e a população tocavam instrumentos como charamela, fagote, trompete, tamboril e flauta. $\mathrm{O}$ berimbau já era utilizado.

No século XVIII a folia de reis como manifestação religiosa permitida pela Igreja. De 24 de dezembro até 06 de janeiro ou 02 de fevereiro, os sítios e as cidades eram percorridos por dois bandos de músicos que saíam somente à noite cantando e louvando o nascimento do Deus Menino e pedindo óbulos. Ainda no século XVII foram muito comuns as glosas ou paródias, sonetos cantados com acompanhamento de violão.

No século XVIII ocorre uma mistura de elementos coreográficos e ritmos afros e ibéricos, especialmente em Salvador. Surge a Fofa (dança), considerada escandalosa por causa dos bailarinos, que na coreografia imitavam o momento do gozo. Pandeiro e viola no acompanhamento musical.

O lundu, canto e dança introduzida pelos escravos de Angola, muito popular em Salvador, continha a umbigada, mais parecida com o batuque dos negros. O refrão e a batida de palmas fundiam o ritmo e a melodia no canto estilo estrofe refrão.

A modinha (portuguesa), canção básica, sentimental, de amor, sobrevive na MPB até hoje. A música de barbeiro, executada pelo negro que cortava o cabelo a serviço do seu senhor. Tocou rabecas, instrumento de sopro e de percussão. Foram precursores das bandas do século XIX.

No século XIX, lundus e modinhas conviveram durante todo século, considerados a seresta dos pobres. Nos solar da burguesia os dois gêneros foram requintados, em estilo bel canto ou como peças teatrais.

A modinha, romântica e sentimental, com suas violas e violões transformaram-se em seresta entre os pobres. Surgem, em meados dos anos oitocentos músicos autores. Nasce a MPB.

No período regencial, no ano de 1831 surgiu a lei que regulamentou o repertório das bandas, com ênfase para marchas e dobrados. Em 1896 é fundada a Banda do Corpo de Bombeiros do Rio de Janeiro, que começou a gravar em 1903. Nas principais cidades do interior também havia bandas.

Ainda no século XIX surgem gêneros musicais novos. Por volta de 1870 surge o frevo em Pernambuco, o maxixe no Rio de Janeiro, bem como o choro, tendo como chorões da época soldados da polícia, componentes de bandas e corporações fardadas.

A música popular brasileira, no início do século $X X$, passou por um período de transição com a popularização dos gêneros europeus, influência da música norte americana, surgimento do samba e reafirmação da música afro nacional.

\section{REVISITANDO A HISTÓRIA DA MPB NO SÉ- CULO XX}

\section{ÉPOCA DE OURO (1929-1945)}

A modinha foi um gênero persistente na MPB. Com o advento do rádio em 1922, a modinha encarnou o gênero operístico e se manteve em evidência até a década de 50 . Augusto Calheiros, Francisco Alves, Vicente Celestino, Orlando Silva e Sílvio Caldas, foram vozes que fizeram muito sucesso sendo fiéis ao gênero e adotando estilo operístico. Mesmo em épocas mais recentes, o estilo permanece vivo, como em Serenata do Adeus (1957), de Vinícius de Moraes, Por quem sonha Ana Maria (1961), de Juca Chaves e Até pensei (1967), de Chico Buarque de Holanda.

Nesse terceiro período, os dois gêneros surgidos na fase anterior e que se beneficiaram com os avanços tecnológicos foram o samba e a marchinha. Além disso, ocorreu o surgimento de um considerável número de artistas de talento numa mesma geração. O samba foi o gênero mais tocado nesse período. Segundo Severiano e Mello (1998, p.86), foram feitos 2176 sambas de um total de 6706 composições, entre 1931 e 1940. As marchinhas somaram 1225. João 
de Barro (1914-2006) e Lamartine Babo (19041963), fixadores da marchinha, e Noel Rosa (1910-1937), maior compositor de samba da primeira metade do século, foram os três grandes compositores do período. Noel Rosa, que viveu apenas 26 anos, produziu mais de 250 composições, a maioria samba.

Sérgio Cabral, um dos maiores historiadores da MPB, costuma destacar o papel de Noel como de um renovador de nossa música popular. Basta comparar a sua obra com o que existia antes dele (1996, p.63). Noel é considerado por Cabral no mesmo nível de Chico Buarque de Holanda e Caetano Veloso. Os três, embora soubessem tocar algum instrumento, não poderiam ser exatamente músicos. No entanto, como renovadores das letras, tiveram de desempenhar a mesma missão também na melodia. Em 30 de suas composições, Noel fez a letra e a música, de excelente qualidade artística. $O$ rádio estimulou o desenvolvimento da MPB.

Em 1923, foi fundada a Rádio Sociedade do Rio de Janeiro e, em 1924, a Rádio São Paulo, além de outras em algumas cidades brasileiras, mas só a partir de 1930, sua abrangência se ampliou em função do interesse político do Estado. Em 1931, o governo Vargas regulamentou a concessão das emissoras de rádio como privativas do Estado, controlando, portanto, todo o sistema de radiodifusão. Em 1932, surgiram as primeiras propagandas do governo, misturadas às músicas tocadas nas rádios.

O disco fonográfico elétrico de boa qualidade, aliado ao rádio como instrumento de marketing, aumentou a tiragem dos discos. O disco, a partir da década de trinta, se tornou um produto de consumo popular. Em 1929, surgiu no Rio de Janeiro uma gravadora concessionária da marca Brunswick, que se dispunha a explorar o mercado com músicas tipicamente brasileiras. Contratou muitos valores novos como Carmen Miranda, Sílvio Caldas, Gastão Formenti e o grupo Bando da Lua, Heitor dos Prazeres e Paulo da Portela. O Bando da Lua teve como integrantes Sinhô e Benedito Lacerda (flautista), além de outros músicos quase anônimos, mas de excelente qualidade, como os violonistas Henrique Brito e Jaci Pereira. Foram para os EUA, acompanhando Carmen Miranda.

$O$ rádio e o disco eletromagnético permitiram que, em 1931, o sucesso de Noel Rosa, Com que roupa, atingisse a impressionante marca de 15 mil discos prensados. Número muito alto para a época, pois o número de possuidores de vitrola ainda não chegava a $5 \%$ da população, calculada em 30 milhões de habitantes (CALDAS, 1989, p.38).

O processo de popularização do samba, estimulado pelo governo marcadamente nacionalista de Vargas, prosseguiu célere no projeto de torná-lo símbolo cultural da nacionalidade. O Departamento de Imprensa e Propaganda, o DIP, criado em 1937, no Estado Novo, controlou o rádio e censurou o samba. As letras das músicas passaram a ter uma censura prévia. Desde 1934, o antecessor do DIP, o Departamento Nacional de Propaganda e Difusão Cultural, baixou normas pelo saneamento das letras das músicas, especialmente o samba, que originariamente foi contestatório e exaltou a malandragem do morador do morro.

Em 1930, surgiu o rádio provido de válvulas elétricas de ampliação, o que permitiu uma recepção mais clara. Os primeiros aparelhos receptores foram os chamados rádios de galena, à base de cristal de galena e outras pequenas peças, além de uma antena esticada entre duas varas de bambu. Com isso, em 1936, surgiu a maior rádio que o Brasil já teve, a Rádio Nacional do Rio de Janeiro, cujo grupo já mantinha os jornais A Manhã e A Noite e a revista Carioca. A Rádio Nacional foi dotada de equipamentos utilizados pelas maiores emissoras do mundo. Em 1940, a Rádio Nacional, os dois jornais e a revista, passaram para as mãos do governo.

A ditadura de Vargas assegurou os meios de comunicação como forma de fortalecer o regime. Em 1935, Getúlio criou "A Hora do Brasil", informativo oficial em que foram intercaladas as notícias com músicas brasileiras. Ao visitar, em 1935, a Argentina e o Uruguai, Vargas levou consigo, na comitiva, um grupo de artistas, inclusive Carmen Miranda, convidada para atuar nos EUA, em 1939. Getúlio Vargas exigiu que o empresário americano levasse também $O$ Bando da Lua.

A partir de 1941, os EUA tornaram mais agressiva a política de trazer para sua órbita os países latino americanos e, para isso, criaram um órgão especial de divulgação do" American Way life'. Hollywood lançou os filmes dirigidos aos países latino americanos. Nesses filmes vieram embutidos os foxes, blues, swings e boogiewoogies, com o som latino de rumbas, congas, boleros e sambas. Esse período, marcou portanto, a influência política interna e externa no meio 
cultural, tendo sido o rádio e o cinema os principais meios difusores de ideologias. Apesar da investida americana no campo cultural, a MPB dominou o mercado durante todo o período Vargas, de acordo com a política nacionalista que queria. O cinema nacional desempenhou seu papel nas instâncias de consagração musical com o desenrolar de filmes musicais conhecidos por chanchadas carnavalescas.

A partir do sucesso do filme "A voz do carnaval", lançado em 1933, desencadeia-se no cinema brasileiro o ciclo da comédia musical, que reinaria por mais de vinte anos. Um lucrativo negócio, esses filmes tinham como chamariz a apresentação na tela de nossos cantores populares, na maioria das vezes interpretando música carnavalesca. Não existindo na época a televisão, o cinema era o veículo ideal para mostrar a imagem desses cantores, conhecida pelo grande público somente através de fotografias publicadas na imprensa (SEVERIANO \& MELLO, 1998, p.86).

Através do cinema, especialmente americano, Carmen Miranda se transformou numa estrela internacional.

A partir da década de 30 , o carnaval e a escola de samba se transformaram em mercadoria. O aproveitamento comercial dessas atividades artístico-culturais estimulou o desenvolvimento do carnaval.

O samba marchado e batucado, cujo nascimento situou-se no período anterior com a composição Deixa falar, feita em 1927, de Ismael Silva, teve o seu nome originariamente ligado a três locais: o bairro do Estácio, situado na zona Norte do Rio, o Bar Apolo e a Praça Onze. Identificaram-se esses locais, porque eles apareceram frequentemente nas letras dos sambas da época.

O Estácio, bairro surgido na segunda metade do século XIX, com a ocupação de aterros, abrigou, desde o início, uma população proletária e de pequeno comércio e atividades artesanais. Os sambas feitos entre 1917 e 1927, especialmente por Sinhô, Donga, China e outros, foram muito bem aceitos, apesar de gravados mecanicamente, porém, foram muito parecidos com os sambas de partido alto de origem baiana dos recôncavos. O pessoal do Estácio, como Alcebíades Barcelos, o Bide, Ismael Silva, Noel Rosa, Baiano, Brancura, Mano Edgar, deram a contribuição definitiva para a carreira comercial do gênero - o samba batucado e marchado do Estácio. O Estácio foi, portanto, o berço do samba de carnaval.

A Praça Onze foi o local de concentração do pessoal do Estácio, durante o carnaval, junto com o pessoal dos outros bairros. O Bar Apolo foi apenas o local de encontro do pessoal "bamba" do Estácio. O bloco idealizado em 1927, por Ismael Silva, Deixa Falar, que desfilou pela primeira vez no ano seguinte, surgiu de uma reunião no Bar Apolo. Depois do Deixa Falar, vieram outros como Estação Primeira de Mangueira e Osvaldo Cruz, que passaram a compor um samba cada vez mais cadenciado para permitir a evolução das escolas. Uma marcha histórica de 1930, de autoria de Ari Barroso foi Dá Nela, porque inaugurou a era dos instrumentos de sopro, principalmente os pistons, na execução das marchinhas. Enfim, os gêneros musicais se dinamizaram na mesma intensidade das inovações tecnológicas e do aperfeiçoamento dos instrumentos musicais. Na euforia do rádio, surgiram os astros e estrelas da nossa música popular. A principal intérprete das músicas de Noel Rosa foi Araci de Almeida (1914-1988), conhecida como A Dama da Central, título atribuído por um locutor carioca. Outros cantores e cantoras também receberam títulos, como Sílvio Caldas - O Caboclinho Querido; Francisco Alves - O Rei da Voz; Orlando Silva - O Cantor das Multidões; Noel Rosa - O Poeta da Vila; Dalva de Oliveira - $A$ voz deliciosa; Carmen Miranda - A Pequena Notável. Destacou-se neste período, o cantor Mário Reis (1907-1981), que aproveitou as vantagens oferecidas pelas gravações eletromagnéticas, para interpretar as canções brasileiras em estilo coloquial, rompendo com a tradição do belcanto italiano, que prevaleceu na MPB.

Dentre os músicos do período, mereceram citação especial Pixinguinha e Radamés Gnatalli por serem os criadores dos padrões de orquestração da música brasileira. Pixinguinha já se referiu bastante no período anterior como contratado, ainda em 1929, pela gravadora Victor, com as funções de instrumentador chefe e ensaiador da Orquestra Victor Brasileira. Pixinguinha recebia melodias empobrecidas e as vestia com arranjos de piano, recuperando sua beleza original. Pixinguinha proveniente dos conjuntos de choro, e dos conjuntos regionais, precursores das orquestras, responsáveis pelo acasalamento do samba ao choro. Transpôs o 
samba-choro e o samba de breque para as formações convencionais das orquestras. Os arranjos de Pixinguinha para canções solo continham uma introdução bastante longa.

Radamés Gnatalli (1906-1988), de formação erudita, interpretou os clássicos e foi compositor de concertos. Aprendeu a tocar música popular para dançar. Em 1934, participou de uma audição de árias clássicas ao lado de Bidu Saião. Em 1934, tornou-se orquestrador permanente da Victor, função para qual Pixinguinha fora contratado em 1929. Participou em 1936, da inauguração da Rádio Nacional, desenvolvendo na casa, a música popular e clássica durante 30 anos. Lábios que beijei (J. Cascata e Leonel Azevedo) gravado em 1937, teve arranjos seus. Aquarela do Brasil fez sucesso depois que Gnatalli lhe colocou um arranjo grandiloqüente. Em 1946, fez uma orquestração para oito violinos, duas violas, celo, oboé, piano, violão, contrabaixo e bateria, das músicas Copacabana e Barqueiro do São Francisco, que fizeram muito sucesso na interpretação de Dick Farney, desencadeando uma revolução nos padrões de orquestração. Gravou em 1964 o LP Retratos, com Jacó do Bandolim. Apresentaram-se várias vezes na Europa com um sexteto que ele próprio organizou. Organizou as trilhas sonoras de diversas novelas da Globo, entre elas Roque Santeiro (1986). Gravou discos com vários parceiros e amigos como Tom Jobim, Dorival Caymmi e Rafael Rabelo, segundo a Enciclopédia da Música Brasileira (1998, p. 329).

Está se fazendo referência detalhada apenas às principais figuras da MPB em cada período, para não se alongar exageradamente o trabalho. Compositores letristas, músicos e cantores, inclusive os intermediários, constarão em anexo, de uma relação nominal, separada por períodos, com a indicação do número da página na Enciclopédia da Música Brasileira.

\section{O PRÉ-BOSSANOVISMO - 1946-1957}

No Brasil, o Estado Novo acabou em 1945 e a sociedade brasileira estava transformada. Não era tão predominantemente agrária, embora os donos da terra constituíssem o grupo mais forte. Nas cidades, havia a burguesia industrial, a classe média e o proletariado. Havia pluralidade. A marcha para a redemocratização produziu nada menos que 12 partidos, sendo os principais o PSD (Partido Social Democrático) que representava as oligarquias geradas pelos interventores getulistas, uma aliança do latifúndio com a indústria monopolista, a UDN, fundada em 7 de abril de 1945, reunindo forças provenientes da burguesia e da classe média para lutar contra Getúlio, e o PTB (Partido Trabalhista Brasileiro) vinculado ao sindicalismo varguista. Dutra, com o apoio dos getulistas do PSD e do PTB, derrotou o udenista brigadeiro Eduardo Gomes. Com restrições, a democracia chegou. Em 7 de maio de 1947, foi cassado o registro do PCB (Partido Comunista do Brasil). Outras restrições da constituição de 1946 foram o impedimento de votar aos analfabetos e aos soldados do escalão inferior, a falta de autonomia sindical e direito de greve. A propriedade da terra manteve o direito inviolável de propriedade.

No âmbito internacional, terminada a guerra, os Estados Unidos ampliaram sua influência no mundo ocidental. O acordo de Breton Woods de 1944, que resultou na criação do Fundo Monetário Internacional (FMI), do Banco Internacional de Reconstrução e Desenvolvimento (BIRD), e, além disso, estabeleceu um sistema monetário internacional baseado no dólar que se tornou a única moeda global e reserva cambial das nações, situou os Estados Unidos no epicentro político e econômico das relações internacionais. Culturalmente, o Brasil passou a receber nítida influência norte-americana.

No plano musical o Brasil urbano aderiu à música de orquestras internacionais que divulgaram ritmos da moda, feitos para dançar: fox, blues, bolero, be-bop, calipso, e o rock'n roll (a partir da década de 50).

As maiores novidades musicais desse período foram o baião e o samba-canção-depressivo, chamado de samba-fossa. Sérgio Cabral em sua obra A MPB na era do rádio (1996, p.96), atribuiu o aboleramento do samba à influência estrangeira que ocorreu na segunda metade da década de 40. Filmes, discos e paradas radiofônicas, foram dominados pelo bolero, pela rumba e pelo mambo. A influência foi tão grande que El Cubanito, cantor de sucesso dos gêneros hispânicos, era carioca, de nome Álvaro Francisco de Paula. Ocorreu a bolerização do samba, chamado de sambolero e que permaneceu em evidência até o final da década de 50 . O baterista misturava tudo e nem se distinguia o sambolero do samba-canção. As letras desses sambas eram quase sempre depressivas. Como esse período foi de transição para a modernidade da 
bossa nova, houve quem o intitulasse de "fossa nova". Esse período foi uma ponte e nele conviveram os veteranos da época de ouro com os iniciantes desta fase, que deram origem à bossa nova.

Antônio Maria (1912-1964) destacou-se nesse período porque foi um dos principais autores do gênero fossa. Estudou piano e francês. Formou-se técnico agrícola e em 1940, mudou-se de Recife para o Rio de Janeiro. Foi locutor esportivo e militou em rádios e jornais. Foi o primeiro diretor de produção da TV Tupi, inaugurada em 1951. Amigo de Dorival Caymmi fez parceria com Fernando Lobo (1915-1996) e Vinícius de Morais (1913-1980). Parceiro também de Manezinho Araújo, Evaldo Gouveia (Canção para ninar gente grande). Antônio Maria entrou no gênero quando este já estava desenvolvido, pois seu primeiro sucesso ocorreu em 1952, com a gravação de Menino grande, samba-acalanto e Ninguém me ama (com Fernando Lobo), gravados por Nora Ney. Outros sucessos seus foram: Suas mãos, O amor e a rosa, Bate coração (com Vinícius de Moraes), Cajueiro doce (com Manezinho Araújo), Onde anda você, Se eu morresse amanhã, Valsa de uma cidade(com Ismael Neto).Dentre os cantores do gênero, o nome mais representativo foi Nora Ney (1922), que começou a fazer sucesso com a música Ninguém me ama (Antônio Maria e Fernando Lobo). Mas, sem as letras de Antônio Maria e a voz de Nora Ney, dificilmente o samba-de-fossa se transformaria em mania nacional.(SEVERIANO \& MELLO, p.241).

Dentre os cantores de sucesso mais identificados com o recém- encerrado período da Época de Ouro, destaques para Francisco Alves, Orlando Silva, Sílvio Caldas, Ciro Monteiro, Gilberto Alves e muitos outros. Dentre os novatos, que tiveram papel decisivo na criação da bossa nova, os cantores Dick Farney, Lúcio Alves, Sílvia Teles, Dóris Monteiro, Luís Cláudio, Agostinho dos Santos e o conjunto vocal Os Cariocas. Cantores/compositores que inovaram foram Tito Madi, Dolores Duran, Billy Blanco, o arranjador Lindolfo Gaya, Antônio Carlos Jobim, Vinícius de Moraes, João Gilberto, Newton Mendonça e Carlos Lira. Grandes instrumentistas deste período que contribuíram para se chegar à bossa nova foram: Johnny Alf (que depois se revelou bom cantor), Chiquinho do Acordeon, Luís Bonfá, Moacir Santos, João Donato e Paulo Moura. Neste período ocorreu o declínio da mú- sica de carnaval. Dos antigos compositores do gênero sobraram apenas João de Barro, Haroldo Lobo e alguns novos, como Klecius Caldas, Armando Cavalcante, Jota Júnior e Luís Antônio, do mesmo nível que os da Época de Ouro.

Os nomes citados dos precursores da bossa nova, não foram os mais consagrados deste período. Como se vivia o auge do rádio, grandes estrelas foram Cauby Peixoto que se rivalizou na condição de cantor e galã com Francisco Carlos; Marlene e Emilinha que viveram o auge da popularidade. Dircinha Batista venceu o primeiro concurso Rainha do Rádio (1948), promovido pela Associação Brasileira de Rádio. Marlene foi eleita Rainha do Rádio em 1949, e nos dois anos seguintes. Outras que disputaram o título durante vários anos, e mantiveram um ciclo de vitórias, foram as irmãs Linda e Dircinha Batista. Esse concurso que já existia antes de 1948, promovido por diversas entidades, foi estimulado pela Rádio Nacional do Rio de Janeiro que passou a explorar a rivalidade entre Emilinha e Marlene, transformando a primeira em cantora exclusiva do programa César de Alencar e transferindo Marlene para o programa de Manuel Barcelos. Emilinha Borba ingressou no elenco da Rádio Nacional em 1944, sempre ligada ao programa de César de Alencar, transmitido para todo país. Durante 27 anos, ininterrupto esteve diretamente ligada ao programa.

\begin{abstract}
Marlene e Emilinha tornaram-se um dos primeiros produtos bem sucedidos da eficiente máquina de criação e divulgação de ídolos, montada no rádio em torno dos programas de auditório, que se estendeu ao cinema através das chanchadas (Enciclopédia da Música Brasileira, 1998, p.104).
\end{abstract}

Com o advento da televisão, a partir de meados da década de 1950, os fãs-clubes organizados pelas rádios perderam força e o título de Rainha do Rádio desapareceu. A música estrangeira tinha forte presença entre nós, especialmente por causa da exagerada comercialização do rádio e dos disc-jóqueis que influenciaram a preferência musical do ouvinte.

$\mathrm{Na}$ busca da obra prima, o professor não pode se esquecer de dois dos maiores nomes do período, Herivelto Martins (1912-1992) e Dalva de Oliveira (1917-1972). Herivelto foi compositor, tocava pistom, cavaquinho e diversos instrumentos musicais, consagrou-se ao formar em 1934, o Trio de Ouro, tendo como componente 
Dalva de Oliveira, com a qual se casou. Herivelto foi responsável por grandes sucessos da MPB como: Praça Onze, Ave Maria no Morro, Segredo (Marino Pinto), A Lapa (Benedito Lacerda), Que rei sou eu, Caminhemos (Roberto Roberti) e Isaura (Roberto Roberti).

Dalva de Oliveira, considerada por grande parte da crítica a melhor cantora brasileira do século XX, trabalhou como faxineira numa escola de dança onde improvisou músicas ao piano. Casou-se com Herivelto Martins em 1937, quando já fazia parte do Trio de Ouro. Recebeu o título de, Rainha da Voz . Seus principais sucessos foram: Brasil, Praça Onze, Ave Maria no morro, Segredo, Tudo acabado, Olhos verdes, Kalu, Bandeira branca, Ave Maria (Vicente Paiva e Jaime Redondo).

Outro gênero musical do período foi o Baião. Originalmente, segundo Mário de Andrade em seu Dicionário Musical Brasileiro (1999, p.36) o baião era executado pelas violas nos cantos de desafio, compondo o chamado rojão. Em 1946, se tornou canção urbana com a composição Baião, de Luís Gonzaga e Humberto Teixeira. A partir da década de 50, e até o advento da bossa-nova, foi o gênero musical brasileiro mais tocado no exterior. $\mathrm{O}$ uso do triângulo como instrumento musical nos EUA, se deu por influência do baião. Valdir Azevedo, em 1950, fez o baião Delicado, que recebeu versões instrumentais de vários maestros americanos. O maior destaque do gênero foi Luiz Gonzaga (1912-1989) sanfoneiro nascido em Exu, Estado de Pernambuco. Gonzaga fez programas nas principais rádios da época e começou a gravar em 1941. Apresentou-se em trajes de vaqueiro nordestino. Gravou como cantor pela primeira vez em 1945 a composição Dezessete e setecentos (c/ Miguel Lima). Nesse ano tornou-se parceiro de Humberto Teixeira, com quem estabeleceu um novo ritmo, o baião com temática voltada para a cultura e costumes nordestinos. Com Humberto Teixeira fez Asa Branca, Meu pé de serra, Mangaratiba, Juazeiro, Paraíba, Qui nem jiló, Baião de dois, Assum preto e Lorota boa, entre outros. Humberto Teixeira teve mais de 400 composições gravadas por intérpretes famosos de nossa música, como Carmélia Alves, Orlando Silva e Araci de Almeida. Humberto Teixeira se elegeu deputado e deixou a parceria. Luís Gonzaga passou a compor com o estudante de medicina José Dantas (1921-1962), com o qual fez Cintura fina, em 1950. Acauã, Dança da moda, Derramaro o gai e Xote das meninas foram frutos dessa parceria. " "Ao aproximar-se o final da década de 50, o público, saturado de boleros e sambas amargos, estava pronto para aceitar novidades mais amenas como a bossa-nova, a jovem guarda e os festivais de canções" (SEVERIANO \& MELLO, 1998, p.243).

Houve uma espécie de rejeição àquele gênero que saturou os ouvintes. Luíz Gonzaga caiu no esquecimento da mídia na década de 60 , apresentando-se em circos e casas baratas de espetáculos. O gosto se quebra, ocorre a evolução, surgindo um movimento musical novo, uma geração de inovadores. Mas não há um rompimento total, um processo de síntese foi efetuado. A bossa nova não rompeu radicalmente com o samba da época de ouro e com a dor de cotovelo do pré-bossanovismo, tão a gosto de Antônio Maria, o que ocorreu nesse processo de passagem foi que as contribuições de um gênero para outro se reforçaram. Apesar das discussões acadêmicas suscitadas pelos críticos, nos momentos de passagem, o gosto musical não perdeu nada, ou antes, afloraram descobertas. Assim como nas ciências, as diferentes contribuições reforçaram-se entre si. Nessas fases de rejeição ao gosto vivido na anterioridade, surgiram os "hinos" revolucionários do novo gênero, caso de Chega de saudade e Desafinado. O tempo parece carcomir os gêneros musicais de certa época; obras primas podem suscitar fascínio sobre gerações subsequentes? Ó abre alas, de Chiquinha Gonzaga foi uma obra apenas intermediária quanto à qualidade artística, mas dificilmente deixará de agradar a todos, mesmo aqueles que nunca a ouviram e nem conheceram o significado de ter sido a primeira marchinha de carnaval da MPB. Em experiências como professor, todas as vezes que foram apresentados aos alunos bons sambas e marchinhas de carnaval da Época de Ouro, o agrado foi geral. Certamente que, todos os gêneros dançantes são de agrado dos adolescentes pós-modernos.

Em janeiro de 1999, o selo Globodisk lançou um álbum que trouxe grandes canções da era pré-bossa nova. O disco não está nas lojas, é vendido apenas por telefone e vendeu mais de 400 mil cópias. O álbum se intitula "Naquele tempo" e trouxe grandes sucessos da música brasileira lançados entre 1947 e 1962. O álbum foi uma verdadeira aula de MPB do período.

2Para saber mais sobre Luíz Gonzaga, consultar Luíz Chagas na série Vozes do Brasil, Martim Claret Editores, 1990. 
Mostrou o que se ouvia no país antes da consagração da bossa nova. Maysa interpretou Ouça, uma das canções de amor e vingança mais fantásticas já composta. Cauby Peixoto interpretou Conceição, a belíssima história da favelada que se prostituiu e se arrependeu. No mesmo nível foram as demais faixas do CD. ${ }^{3}$

Algumas novidades tecnológicas importantes surgiram no início da década de 50 . O long-playing (LP) lançado no Brasil em 1953 apareceu três anos antes nos EUA. Outra novidade, lançada em 1953, foi o sistema de 45 rpm que não vingou no mercado brasileiro. O LP, micro sulco de 33 1/3 rpm, fabricado em vinil, só começou a suplantar o antigo sistema a partir de 1958. O Brasil foi o quarto país do mundo a lançar o LP. Em 1960, surgiu o primeiro disco 78 rpm inquebrável, até então aqueles discos usavam como matéria-prima a goma laca. Em novembro de 1984, o Brasil entrou na era da gravação digital com o lançamento pela Polygram do primeiro $C D$. Outra novidade importante no mundo das comunicações foi a inauguração, no dia 18 de setembro de 1950, da primeira televisão brasileira, a TV Tupi de São Paulo. Em 20 de janeiro de 1951 foi inaugurada a TV Tupi do Rio, pertencente ao mesmo grupo de São Paulo, do jornalista Assis Chateaubriand. Enquanto isso, nossos músicos perseguiam a modernização, especialmente com a utilização dos recursos da música norte-americana, especialmente o jazz. Merece especial destaque, na americanização de nossos ritmos, o pianista Johnny Alf que se apresentava cantando e tocando piano, utilizando dissonâncias pouco comuns em nosso ritmo, e o cantor e pianista de grandes méritos, Dick Farney, que passou a tratar as novas composições brasileiras como se fossem be-bops (CAMPOS, 1993, p.19). Newton Mendonça (1927-1960) pianista, João Donato (1934) e outros músicos de Copacabana, zona sul do Rio, faziam experiências novas com boa receptividade de parte do grande público. No dizer de Zuza Homem de Mello, autor de Canção no tempo, as músicas desse período saturaram o público com seus sambas e boleros amargos, e este estava pronto para receber novidades mais ou menos como a bossa nova, a jovem guarda e os festivais de canções. Nossas músicas estavam prontas para a modernização e a década

${ }^{2} \mathrm{~A}$ revista Veja traz uma resenha à respeito desse lançamento em seu número 33. de 20.1.1999, p.121. de 1960 aconteceu como a mais significativa e renovadora da MPB do século XX.

\section{CONSIDERAÇÕES FINAIS}

Depois do período pré bossanovista (1946-1957), a MPB vai atingir o seu auge. Uma renovação virtuosa, tão ampla, difícil de ser explicada, especialmente escalada qualitativa de novos gêneros musicais, nomes representativos e inovações tecnológicas.

Surge em 1958 a bossa nova, com a música símbolo "Chega de Saudade" (Vinícius de Moraes e Antonio Carlos Jobim), cantada por João Gilberto. A Tropicália, nos anos de 1967 e 1968, cuja música manifesta foi Alegria Alegria (Caetano Veloso), teve como principais nomes do movimento baiano Caetano e Gil, Tom Zé, Capinan e Torquato Neto.

O samba tradicional ressurgiu no final da década de 1960 e ganhou força na década de 1970. Os nomes mais representativos foram Cartola, Nelson Cavaquinho, Paulinho da Viola, Elton Medeiros, Candeia, Zé Keti, Martinho da Vila, Clementina de Jesus.

Variante do samba foi o sambalanço, meio termo entre a bossa nova e o samba tradicional. Os principais nomes foram Miltinho, Dóris Monteiro, Luis Bandeira, Luis Antonio e Luis Reis.

O rock brazuca da década de 1970 desenvolveu o movimento Jovem Guarda com Roberto Carlos, Erasmo Carlos e Wanderleia dentre outros. Os Mutantes e Rita Lee representaram a vertente inglesa do rock dos anos sessenta e setenta.

O samba enredo despontou a partir de 1960. Desaparecem os sambas e marchinhas de carnaval. Muito forte durante a pós-bossa nova foi o brega romântico através do samba canção, em geral depressivo, muito bem cantado por Nelson Gonçalves, Angela Maria, Cauby Peixoto e outros.

Dentre as inovações tecnológicas que alteraram a forma de ouvir e consumir música, o cassete e os gravadores caseiros e de fita magnética. A expansão da televisão incrementou a indústria da diversão.

O fim do disco de 78 rpm e a decadência do rádio completam o panorama tecnológico do auge musical que aconteceu então. Enfim, a pré-bossa nova foi a ponte que levou a MPB ao seu maior momento - a Era dos festivais (1958- 
1972).

\section{REFERÊNCIAS}

AGUIAR, J. Nada além, a vida de Orlando

Silva. 2. ed., São Paulo: Globo, 1995. 325p.

ALENCAR, E. de. O carnaval carioca através da música. 3. ed. Rio de Janeiro: Francisco Alves, 1979. 586p.

AMARAL, K. F. do. Pesquisa em música e educação. São Paulo: Loyola, 1991. 119p.

AUGUSTO, A. Moreira da Silva, o último dos malandros. Rio de Janeiro: Record, 1996. $358 p$.

BARCINSKI, A., GOMES, S. Sepultura, toda história. São Paulo: Ed.34, 1999. 208 p.

BARROS, J. C. de. Nelson Cavaquinho e Pixinguinha. Revista Veja, São Paulo: v.32, n.46, p.145. nov. 1999.

BILLARD, F. No mundo do jazz: das origens à década de 50. São Paulo: Companhia das Letras, 1990. 283p. (A Vida Cotidiana).

BLANCO, B. Tirando de letra e música/Billy Blanco. Rio de Janeiro: Record, 1996. 147p.

BRASIL. LEI diretrizes e bases da educação nacional. São Paulo: Saraiva, 1997.

BRITO. B. R. Bossa Nova. In: Balanço da

Bossa. São Paulo: Perspectiva, 1993. p. 17-40

CABRAL, S. MPB na era do rádio. São Paulo: Moderna, 1996. 111p.

Antonio Carlos Jobim: uma biografia. Rio de Janeiro: Relume Dumará, 1997. 545p.

As escolas de samba do Rio de

Janeiro. Rio de Janeiro: Lumiar, 1996. 448p.

Elisete Cardoso, uma vida. 2.ed., Rio de Janeiro: Lumiar, s.d. 404p.

No tempo de Almirante. Rio de Janeiro: Lumiar, 1990. 229p.

No tempo de Ari Barroso. Rio de Janeiro: Lumiar, s.d. 467p.
Pixinguinha, vida e obra. Rio de

Janeiro: Lumiar, 1974. 247p.

CAMPOS, A. (org.). Balanço da bossa e outras bossas. 5.ed., São Paulo: Perspectiva, 1993. 354p.

CASTRO, R. Chega de saudade. A história e as histórias da bossa nova. 2.ed., São Paulo: Companhia das Letras, 1990. 461p.

CAYMMI, D. Cancioneiro da Bahia. 4.ed., São Paulo: Martins, s.d. 189p.

CAZES, H. Choro, do quintal ao municipal. São Paulo: Ed.34, 1998. 208p.

CDTECA FOLHA, da música brasileira, Folha de São Paulo. Bossa nova, a História do movimento musical que mudou a MPB. São Paulo: Publifolha, 1998, 15 p. Edição Especial.

COSTA, F. M. da. Nelson Cavaquinho, enxugue os olhos e me dê um abraço. Rio de Janeiro: Relume Dumará, 2000,158p.

CYNTRÃO, S. H. (org.). A forma da festa, tropicalismo: a explosão e seus estilhaços. Brasília: UNBrasilia, 2000. 236p.

DAPIEVE, A. Brock, o rock brasileiro dos anos 80. 2.ed., São Paulo: Ed.34, 1996. 224p.

Renato Russo, o trovador solitário. Rio de Janeiro: Relume- Dumará, Prefeitura, 2000. 183p.

DREYFUS, D. O violão vadio de Baden

Powell. São Paulo: Ed. 34, 1999. 384 p.

ENCICLOPÉDIA, música brasileira. 2. ed., São Paulo: Publifolha, 1998. 887p.

EXECUTIVO que trocou os números pelas notas. Abril Cultural, São Paulo, 1982. Coleção História da MPB, Gilberto Gil (fascículo).

FARO, F., BOTEZELLI, J. C.; PELÃO, A. P. (orgs.). A música brasileira deste século por seus autores e intérpretes. São Paulo: Sesc, 2000, 2 vs, v.1, 224p.

A música brasileira deste século por seus autores e intérpretes. São Paulo: Sesc, 2000, 2vs, v.2, 256 p. 
GALVÃO, L. Novos e baianos, anos 70. São

Paulo: Ed. 34, 1997. 288p.

GARCIA, W. Bim bom, a contradição sem conflitos de João Gilberto. São Paulo: Paz e Terra, 1999. $221 \mathrm{p}$.

GIL, G. Todas as letras. São Paulo:

Companhia das Letras, 1996.

JAYME, S. P. (org.) Memórias da MPB.

Londrina: UEL, 2000. 269p.

LEÃO, T. Guitarras em fúria. São Paulo:

Ed.34, 1997. 232p.

LOUZEIRO, J. Elza Soares, cantando para não enlouquecer. São Paulo Globo, 1997. $426 p$.

MACIEL, L. C. Geração em transe: memórias do tempo do tropicalismo. 2.ed., Rio de Janeiro: Nova Fronteira, 1996. 275p.

MARTINS, S. Clássicos sertanejos. Revista Veja, São Paulo, v.29, n.34, 1996.

MASSON, C. Jovem guarda negra. Revista Veja, São Paulo, v.29, n.21, maio 1996. p.138.

MASSON, C., OKKI, S. e. Sons do Brasil. Veja, São Paulo. v.30, n.49, nov.1997. p.138.

MATHEUS, R. R. de R. Araci Cortez: linda flor - MPB 12. Rio de Janeiro: Funarte, INM, 1984. $198 p$

MATOS, C. Acertei no milhar, samba e malandragem na época de Getúlio Vargas. São Paulo: Brasiliense, 1993, p.219.

MEDAGLIA, J. Balanço da bossa nova. In: CAMPOS, A. Balanço da bossa e outras bossas. 5. ed., São Paulo: Perspectiva, 1993, pp.67-123

MENDONÇA, A. R. Carmen Miranda foi a Washington. Rio de Janeiro: Record, 1999. 209p.

MORAES, J. J. O que é música. São Paulo: Brasiliense, 1983. 103p.

MOTA, N. Música humana música. Rio de Janeiro: Salamandra, 1980. 281p.
Noites tropicais, solos, improvisos e memórias musicais. Rio de Janeiro, Objetiva, 2000. 461p.

MULHER mais bem paga do mundo: Carmen Miranda. Folha do Norte, São Paulo. s.n. 23 dez / 1954.

PASSOS, S.; BUDA, T. Raul Seixas, uma antologia. São Paulo: Martin Claret, 2000. 366p.

PUGIALLI, R. No embalo da jovem guarda. São Paulo: Ampersand, 2000. 208 p.

RATTON, M. Criação de música e sons no computador: uma abordagem prática para a utilização do computador em aplicações musicais. Rio de Janeiro: Campus, 1995. 195p.

RENNÓ, C. (org.). Gilberto Gil, todas as letras. São Paulo: Companhia das Letras, 1996. 390p.

RODRIGUES FILHO, L. (org.). Foi assim, o cronista Lupicínio conta as histórias das suas músicas. Porto Alegre: L \& PM,1995. $120 p$.

SALVADORI, M. A. B. Malandras canções brasileiras. Revista Brasileira de História, São Paulo, v.7, n.13, p.103-124, set. 86/ fev. 87.

SANCHES, N.; CAMACHO, M. Roqueiro de peso. Revista Veja, São Paulo: v.31, n.4, jan. 1998. p.90.

SANCHES, P. A. As sete vidas de Lobão. Folha de São Paulo, São Paulo, Ilustrada, c. 4, p. 1, 3 nov. 1999.

. Tropicalismo, decadência bonita do samba. São Paulo: Bãotempo, 2000. 357p.

SEVERIANO, J.; MELLO, Z. H. de. A canção no tempo, 85 anos de músicas brasileiras (1901-1957). 2. ed., 1998, 2v, v.1. São Paulo: Ed.34, 367p.

A canção no tempo, 85 anos de música brasileira (1958-1985). São Paulo: Ed. 34, 1998. 2v. v.2. 368 p.

TINHORÃO, J. R. História social da música popular brasileira. 2.ed., São Paulo: Ed.34, 
1999. 368p.

Música em debate. 3. ed., São Paulo:

Ed. 34, 1997. 192p.

Pequena História da música popular

brasileira: da modinha ao tropicalismo. 6. ed., 1986. 397p.

VASCONCELOS, A. 1926. Raízes da música

popular brasileira (1500-1889). São Paulo:

Martins, 1977. 349p.

VELOSO, C. Verdade tropical. São Paulo:

Companhia das Letras, 1997 524p.

VIANNA, H.; BALDAN, E. Música do Brasil.

São Paulo: Abril, 2000. 220p.

VIANNA JÚNIOR, H. O mistério do samba. 3. ed., Rio de Janeiro: Ed. UFRJ, 1995. 196p.

\section{MPB - LA ÉPOCA DE ORO (1929-1945) Y LA PRÉ BOSSA (1946-1957)}

Resumen: La Época de Oro de la MPB fue suplantada en importancia sólo por la Era de los Festivales (1958-1973). Se evalúa la grandiosidad del período por las sambas y marchitas que representaron cincuenta por ciento de las grabaciones del período. Por los extraordinarios compositores Noel Rosa, João de Barro y Lamartine Babo. De ese período de los cuatro grandes intérpretes - Francisco Alves, Carlos Galhardo, Silvio Caldas y el mayor de todos, Orlando Silva. Pixinguinha y Radamés Gnatalli crearon los estándares de orquestación de la música brasileña. Ari Barroso produjo Aquarela do Brasil, la música más importante del siglo XX, y Carmem Miranda fue el nombre de mayor destaque. El período pre bossa nova fue marcado por la samba, canción depresiva y el baião, como novedades. Se adoptó géneros internacionales como el fox y el blues; bolero, calipso, rumba como géneros latinos. Finalmente el rock'n roll. Emergen grandes cantantes, compositores que innovan en los temas y en la forma de cantar. Dorival Caymmi, Tom Jobim, Vinicius de Moraes fueron exponentes del período. La pre bossa nova preparó el advenimiento de la MPBM - Moderna Música Popular Brasileña, representada por tres grandes movimientos musicales innovadores: la bossa nova, la joven guardia y la tropicália.

PALABRAS Clave: Cultura popular; Géneros musicales; Movimientos musicales; Musica Popular Brasileña. 